University of Nebraska - Lincoln

DigitalCommons@University of Nebraska - Lincoln

2013

\title{
The mid-domain effect: It's not just about space
}

Andrew D. Letten

S. Kathleen Lyons

Angela T. Moles

Follow this and additional works at: https://digitalcommons.unl.edu/bioscifacpub

Part of the Biology Commons, and the Terrestrial and Aquatic Ecology Commons

This Article is brought to you for free and open access by the Papers in the Biological Sciences at

DigitalCommons@University of Nebraska - Lincoln. It has been accepted for inclusion in Faculty Publications in the Biological Sciences by an authorized administrator of DigitalCommons@University of Nebraska - Lincoln. 


\title{
The mid-domain effect: It's not just about space
}

\author{
Andrew D. Letten, ${ }^{1}$ S. Kathleen Lyons, ${ }^{2}$ \\ and Angela T. Moles ${ }^{3}$
}

1 Australian Wetlands, Rivers and Landscapes Centre, School of Biological, Earth and Environmental Sciences, University of New South Wales, Sydney, NSW Australia,

2 Department of Paleobiology, National Museum of Natural History, Smithsonian Institution, Washington, DC 20013-7012, USA,

3 Evolution \& Ecology Research Centre, School of Biological, Earth and Environmental Sciences, The University of New South Wales, Sydney, NSW Australia

Corresponding author - A. D. Letten, email: a.letten@unsw.edu.au

Ecologists and biogeographers have long sought to understand how and why diversity varies across space. Up until the late 20th century, the dominant role of environmental gradients and historical processes in driving geographical species richness patterns went largely undisputed. However, almost 20 years ago, Colwell \& Hurtt (1994) proposed a radical reappraisal of ecological gradient theory that called into question decades of empirical and theoretical research. That controversial idea was later termed the 'the mid-domain effect': the simple proposition that in the absence of environmental gradients, the random placement of species ranges within a bounded domain will give rise to greatest range overlap, and thus richness, at the center of the domain (Colwell \& Lees, 2000) (Fig. 1a). The implication of this line of reasoning is that the conventional null model of equal species richness regardless of latitude, elevation or depth should be replaced by one where richness peaks at some midpoint in geographical space.

Published in Journal of Biogeography 40 (2013), pp 2017-2019.

doi: $10.1111 /$ jbi.12196

Copyright ( 2013 John Wiley \& Sons Ltd. Used by permission. 


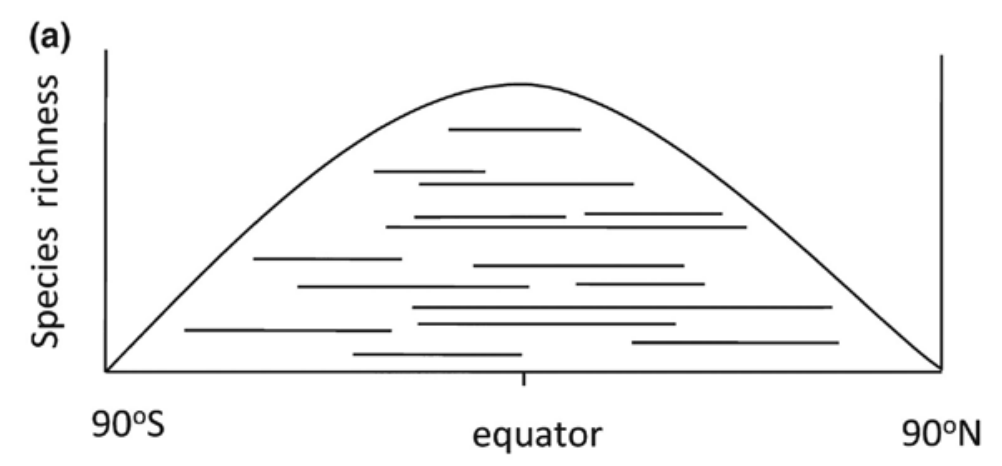

(b)
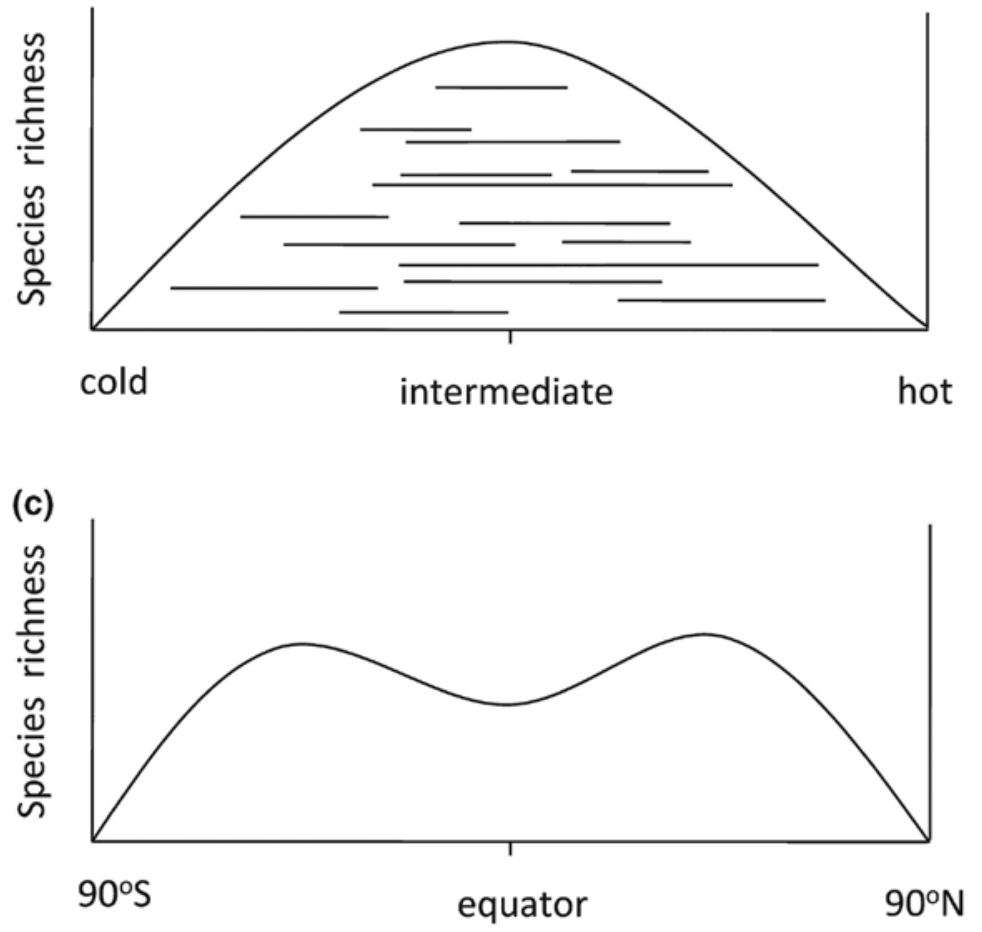

Figure 1. (a) The traditional mid-domain model (Colwell \& Hurtt, 1994); (b) the same mid-domain model applied to a temperature-based domain; (c) the predictions from (b), mapped back on to geographical space. The curve in panel (c) is an example only. Its real shape would depend on the specifics of the temperature domain considered [most importantly, the slope of the temperature gradient (Brayard et al., 2005), whether you define the domain according to lethal temperatures or mean temperatures, and what temporal scale you consider temperature data over]. The most appropriate options would depend on the biology of the taxa being considered. 
In spite of the rapid accumulation of numerous empirical datasets conforming to the mid-domain null model across a wide range of taxa (Colwell et al., 2004), opposition to the mid-domain hypothesis was staunch (e.g. Hawkins et al., 2005; Zapata et al., 2005). Opponents cited the porosity of geographical domains and the purported 'smuggling in' of environmental factors into the range size frequency distribution used to generate mid-domain null models as logical flaws (Hawkins et al., 2005). The mid-domain debate reached its own peak in 2004-2005 with a series of reviews (e.g. Colwell et al., 2004), comments (Hawkins et al., 2005; Zapata et al., 2005) and replies (Colwell et al., 2005) in the American Naturalist. Despite little resolution, the debate around the mid-domain effect subsequently waned. However, the number of recent research papers (26 from 2011-2012 according to Web of Science) citing the mid-domain effect stands testament to its continued influence on ecological discourse.

Our intention here is to draw attention to a neglected, yet important manifestation of the mid-domain effect, namely the application of mid-domain models (also referred to as geometric constraint models) to non-spatial domains. If individual species have ranges that exist not just in geographical space but also in environmental factors, such as temperature, rainfall, $\mathrm{pH}$, productivity or disturbance, shouldn't we also expect mid-domain richness peaks along non-spatial gradients? A mid-domain model applied to non-spatial gradients predicts the maximum potential richness for every value of an environmental factor. As with spatial mid-domain models, realized richness would probably be less, but the limits to richness are still predicted to be humpshaped. Indeed, hump-shaped relationships emerge with remarkably high frequency across various non-spatial gradients. For instance, two of ecology's most fundamental, albeit controversial theories - the productivity-diversity relationship and the intermediate disturbance hypothesis - predict mid-domain peaks in species richness. However, the potential of non-spatial mid-domain models has gone largely ignored.

The notion that mid-domain models may have non-spatial applications has been noted before (e.g. Colwell \& Lees, 2000). However, only six studies have actually employed mid-domain models to inspect richness responses along non-spatial gradients, including sea temperature (Brayard et al., 2005; Beaugrand et al., 2013), estuarine temperature and salinity (Carranza et al., 2008), light (Lusk et al., 
2006) and time (Morales et al., 2005; Tiwari et al., 2005). All six studies found evidence for a non-spatial mid-domain effect. Given the paradigm-shifting ramifications of a mid-domain null expectation along any non-spatial gradient, we venture there is an imperative for further quantitative inquiry.

The dearth of studies that have investigated non-spatial mid-domain effects points to either a lack of awareness of their potential relevance or an uncertainty in their implementation. Having addressed the former above, below we briefly consider the latter, beginning with an illustrated example. Consider a temperature gradient, from the coldest surface temperatures on Earth to the hottest temperatures. The maximum and minimum temperatures define the boundaries of the domain. Species occupy portions of this domain (for instance, emperor penguins occupy a small range towards the cold end of the scale). To apply mid-domain models to temperature gradients, species' observed temperature ranges are randomly assigned to the domain. As with the spatial ranges, assuming species' temperature ranges are of intermediate size with respect to the temperature domain, mid-domain models will predict the greatest number of overlapping ranges in the middle of the domain; that is, they predict the greatest species richness at intermediate temperatures (Fig. 1b). Examining the latitudinal gradient in species richness solely from the perspective of a middomain effect along a temperature gradient, we thus predict species richness to peak somewhere around mid-latitudes, i.e. a bimodal pattern (Fig. 1c). Although a mid-latitude richness peak is at odds with the wealth of empirical data evidencing a monotonic increase in richness towards the equator, in some environments the predicted bimodal gradient actually occurs with extraordinary frequency (Rutherford et al., 1999). Indeed, Brayard et al. (2005) demonstrated that an observed bimodal latitudinal richness gradient in marine plankton can arise from the combination of a geographical and a thermal mid-domain effect. As such, under warming temperatures, combined spatial and non-spatial mid-domain models may be expected to predict a poleward shift in transequatorial richness peaks for some taxa.

Although we used temperature as an example, in reality, species distributions are almost always determined by a range of factors acting in concert. Thus, we need a way to combine information from models based on different factors. A simplified approach would be 
first to map the predictions from the temperature domain onto latitudinal space by taking the predicted number of species for each temperature, and mapping them on to the locations in the spatial domain which experience that temperature. The same process can be applied to predictions based on net primary productivity, rainfall, or any other variable for which the spatial distribution is known. Once the predictions are in a common currency (e.g. the number of species expected at a given location), we can use standard statistical techniques (e.g. generalized linear models) to investigate the proportion of variation in the observed data explained by models based on the different variables, and by their interactions. Predictions from a purely spatial mid-domain model could be included as one of the variables of interest. Examining residual variation from predictions generated by these multiple-factor mid-domain models should lend insight into the underlying causes of diversity gradients in a more powerful way than was possible with a single variable alone. There is, of course, considerable scope for future work exploring different methodological approaches to non-spatial mid-domain models on both real and simulated datasets.

Several of the challenges encountered in applying spatial mid-domain models will also apply to non-spatial mid-domain models, for example what is the most appropriate approach to compiling the range size frequency distribution, how should the domain limits be defined, and what is the appropriate taxonomic resolution? In addition, given the existence of robust ecological theory invoking tradeoffs that generate just the same kind of unimodal patterns anticipated by non-spatial mid-domain models, distinguishing stochastic phenomena from genuine ecological responses will necessitate careful statistical analyses. Nevertheless, we suggest that the potential ramifications of non-spatial mid-domain models are of sufficient magnitude to warrant much greater attention.

\section{References}

Beaugrand, G., Rombouts, I. \& Kirby, R.R. (2013) Towards an understanding of the pattern of biodiversity in the oceans. Global Ecology and Biogeography, 22, 440-449. 
Brayard, A., Escarguel, G. \& Bucher, H. (2005) Latitudinal gradient of taxonomic richness: combined outcome of temperature and geographic mid-domains effects? Journal of Zoological Systematics and Evolutionary Research, 43, 178-188.

Carranza, A., Colwell, R.K. \& Rangel, T.F.L.V.B. (2008) Distribution of megabenthic gastropods along environmental gradients: the mid-domain effect and beyond. Marine Ecology Progress Series, 367, 193-202.

Colwell, R.K. \& Hurtt, G.C. (1994) Nonbiological gradients in species richness and a spurious Rapoport effect. The American Naturalist, 144, 570-595.

Colwell, R.K. \& Lees, D.C. (2000) The mid-domain effect: geometric constraints on the geography of species richness. Trends in Ecology and Evolution, 15, 70-76.

Colwell, R.K., Rahbek, C. \& Gotelli, N.J. (2004) The mid-domain effect and species richness patterns: what have we learned so far? The American Naturalist, 163, E1-23.

Colwell, R.K., Rahbek, C. \& Gotelli, N.J. (2005) The mid-domain effect: there's a baby in the bathwater. The American Naturalist, 166, E149-E154.

Hawkins, B.A., Diniz-Filho, J.A.F. \& Weis, A.E. (2005) The mid-domain effect and diversity gradients: is there anything to learn? The American Naturalist, 166, E140-143.

Lusk, C.H., Chazdon, R.L. \& Hofmann, G. (2006) A bounded null model explains juvenile tree community structure along light availability gradients in a temperate rain forest. Oikos, 112, 131-137.

Morales, M.A., Dodge, G.J. \& Inouye, D.W. (2005) A phenological mid-domain effect in flowering diversity. Oecologia, 142, 83-9.

Rutherford, S., D'Hondt, S. \& Prell, W. (1999) Environmental controls on the geographic distribution of zooplankton diversity. Nature, 400, 749-753.

Tiwari, M., Bjorndal, K.A., Bolten, A.B. \& Bolker, B.M. (2005) Intraspecific application of the mid-domain effect model: spatial and temporal nest distributions of green turtles, Chelonia mydas, at Tortuguero, Costa Rica. Ecology Letters, 8, 918-924.

Zapata, F.A., Gaston, K.J. \& Chown, S.L. (2005) The mid-domain effect revisited. The American Naturalist, 166, E144-148. 